\title{
A practical guide to the handling and administration of talimogene laherparepvec in Europe
}

This article was published in the following Dove Press journal:

OncoTargets and Therapy

2 August 2017

Number of times this article has been viewed

\section{Kevin J Harrington' \\ Olivier Michielin² \\ Josep Malvehy, \\ Isabella Pezzani Grüter ${ }^{5}$ \\ Lorna Grove ${ }^{6}$ \\ Anna Lisa Frauchiger ${ }^{7}$ \\ Reinhard Dummer ${ }^{7}$}

'NIHR Biomedical Research Centre, The Institute of Cancer Research/ The Royal Marsden Hospital, London, UK; ${ }^{2}$ Department of Oncology, Centre Hospitalier Universitaire Vaudois, Lausanne, Switzerland; ${ }^{3} \mathrm{H}$ ospital Clinic de Barcelona, IDIBAPS, CIBER de enfermedades raras, Barcelona, Spain; ${ }^{4}$ FIS del Instituto de Salud Carlos III, Madrid, Spain; ${ }^{5}$ Department of Research and Development, Amgen Switzerland AG, Zug, Switzerland; ${ }^{6} \mathrm{Head}$ and Neck Unit, The Royal Marsden Hospital, London, UK; ${ }^{7}$ Skin Cancer Centre/Dermatology Clinic, Universitätsspital Zürich, Zurich, Switzerland
Correspondence: Kevin J Harrington NIHR Biomedical Research Centre, The Institute of Cancer Research/The Royal Marsden Hospital, 237 Fulham Road, London SW3 6JB, UK

Tel +44 2071535157

Fax +442078082235

Email kevin.harrington@icr.ac.uk

\begin{abstract}
Talimogene laherparepvec is a herpes simplex virus-1-based intralesional oncolytic immunotherapy and is the first oncolytic virus to be approved in Europe. It is indicated for the treatment of adults with unresectable melanoma that is regionally or distantly metastatic (stage IIIB, IIIC, and IVM1a) with no bone, brain, lung, or other visceral disease. Talimogene laherparepvec is a genetically modified viral therapy, and its handling needs special attention due to its deep freeze, cold-chain requirements, its potential for viral shedding, and its administration by direct intralesional injection. This review provides a practical overview of handling, storage, and administration procedures for this agent in Europe. Talimogene laherparepvec vials should be transported/stored frozen at a temperature of $-90^{\circ} \mathrm{C}$ to $-70^{\circ} \mathrm{C}$, and once thawed, vials must not be refrozen. Universal precautions for preparation, administration, and handling should be followed to avoid accidental exposure. Health care providers should wear personal protective equipment, and materials that come into contact with talimogene laherparepvec should be disposed of in accordance with local institutional procedures. Individuals who are immunocompromised or pregnant should not prepare or administer this agent. Talimogene laherparepvec is administered by intralesional injection into cutaneous, subcutaneous, and/or nodal lesions that are visible, palpable, or detectable by ultrasound. Treatment should be continued for $\geq 6$ months. As with other immunotherapies, patients may experience an increase in the size of existing lesion(s) or the appearance of new lesions (ie, progression) prior to achieving a response ("pseudo-progression"). As several health care professionals (eg, physicians [dermatologists, surgeons, oncologists, radiologists], pharmacists, nurses) are involved in different stages of the process, there is a need for good interdisciplinary collaboration when using talimogene laherparepvec. Although there are specific requirements for this agent's storage, handling, administration, and disposal, these can be effectively managed in a real-world clinical setting through the implementation of training programs and straightforward standard operating procedures.
\end{abstract}

Keywords: herpes simplex virus, intralesional injection, melanoma, oncolytic immunotherapy, practical considerations, talimogene laherparepvec

\section{Introduction}

Due to the high incidence of skin (cutaneous/subcutaneous) and lymph node metastases in melanoma, direct intralesional injection is clinically feasible in many patients $^{1,2}$ and could, for example, be an option in patients with in-transit disease. The aim of intralesional oncolytic immunotherapy is to regress the injected lesion while also producing immunologic effects at distant sites in uninjected lesions. ${ }^{3}$ This can be achieved when the injected agent induces regional and systemic immune responses to melanoma antigens. Various intralesional therapies have been tested in melanoma, including Bacillus Calmette-Guérin inoculation, ${ }^{4}$ rose Bengal, ${ }^{5}$ cytokinebased therapies (eg, interleukin [IL]-2, ${ }^{6}$ interferon, ${ }^{7}$ granulocyte-macrophage 
colony-stimulating factor $[\mathrm{GM}-\mathrm{CSF}],{ }^{8}$ and naked plasmid DNA encoding IL-12 ${ }^{9}$ ), and virus-based therapies like the herpes simplex virus type-1 (HSV-1)-based agents HSV $1716^{10}$ and HF $10^{11}$ and Coxsackievirus A21. ${ }^{12}$ Furthermore, adenovirus ${ }^{13}$ - and measles virus ${ }^{14}$-based therapeutics have been evaluated as potential treatments for cutaneous lymphomas.

\section{Talimogene laherparepvec - a new intralesional oncolytic immunotherapy for melanoma}

Oncolytic viruses aim to selectively infect, replicate within, and lyse tumor cells, without harming normal tissues. ${ }^{15-17}$ Talimogene laherparepvec (IMLYGIC ${ }^{\circledR}$, Amgen Europe B.V., Breda, the Netherlands) is the first intralesional oncolytic immunotherapy based on HSV- $1^{18}$ with proven efficacy in a Phase III clinical trial, ${ }^{19}$ although other HSV-1-based melanoma therapies (eg, HF10 ${ }^{11}$ and HSV $1716^{10}$ ) are in development. Talimogene laherparepvec is the first treatment of its type to be approved in Europe ${ }^{20}$ and the US. ${ }^{21}$ It is indicated in Europe for the treatment of adults with unresectable melanoma that is regionally or distantly metastatic (stage IIIB, IIIC, and IVM1a) with no bone, brain, lung, or other visceral disease. ${ }^{22}$ In the UK, the National Institute for Health and Care Excellence has recently approved the reimbursement of talimogene laherparepvec in patients with the same disease stage for whom systemically administered immunotherapy is not suitable (treatment must be provided in the context of a patient access scheme).$^{20}$

Various genetic modifications (ie, deletion of the infected cell protein $[I C P] 34.5$ and ICP47 genes and insertion of the human GM-CSF gene) support the selective replication of talimogene laherparepvec in tumor cells and its antitumor activity (Table 1). ${ }^{23}$ The proposed mechanism of action com-

Table I Characteristics/modifications of talimogene laherparepvec and their impact on safety and antitumor response

\begin{tabular}{|c|c|}
\hline Characteristic/modification & Rationale \\
\hline $\begin{array}{l}\text { Deletion of ICP34.5 (neurovirulence } \\
\text { factor) }\end{array}$ & $\begin{array}{l}\text { Mediates tumor-selective } \\
\text { replication }\end{array}$ \\
\hline Deletion of ICP47 & $\begin{array}{l}\text { Restores antigen presentation } \\
\text { (enhances the antitumor } \\
\text { immune response) }\end{array}$ \\
\hline Early/increased USII expression & $\begin{array}{l}\text { Increases replication of } \\
\text { ICP34.5-deleted HSV }\end{array}$ \\
\hline Insertion of human GM-CSF gene & $\begin{array}{l}\text { Enhances the antitumor } \\
\text { immune response }\end{array}$ \\
\hline Use of a new HSV-I strain (JSI) & Improves tumor cell lysis \\
\hline Intact thymidine kinase gene & $\begin{array}{l}\text { Fully susceptible to acyclovir } \\
\text { and ganciclovir }\end{array}$ \\
\hline
\end{tabular}

Note: Data from Liu et al. ${ }^{23}$

Abbreviations: GM-CSF, granulocyte-macrophage colony-stimulating factor; HSV-I, herpes simplex virus-I; ICP, infected cell protein. prises both local and systemic effects (Figure 1). ${ }^{15,17,18,23-26}$ Selective replication of talimogene laherparepvec within infected tumor cells results in oncolysis and the release of progeny viruses, which can then infect additional tumor cells in the surrounding area, repeating the cycle. ${ }^{17,24,25}$ The oncolytic release of viral and tumor-specific antigens prompts dendritic cell recruitment, while release of the cytokine GMCSF leads to dendritic cell maturation. Dendritic cells then process and present tumor antigens to $\mathrm{T}$ cells in the lymph nodes, ${ }^{15,26}$ potentially inducing the activation and expansion of tumor-specific $\mathrm{CD} 8^{+} \mathrm{T}$ cells and the initiation of a tumorspecific systemic immune response. . $^{15,23,26}$

Although the early phase trials of talimogene laherparepvec included patients with a variety of solid tumors, ${ }^{23,27}$ clinical development to date has focused on melanoma. Melanoma was selected due to the availability of accessible lesions for direct injection and because an active role for the immune system has been implicated in this type of cancer. In the randomized open-label Phase III Oncovex (GM-CSF) Pivotal Trial in Melanoma (OPTiM) trial (NTC00769704), talimogene laherparepvec statistically significantly improved durable response rates (DRRs; continuous response of $\geq 6$ months beginning within the first 12 months of therapy, and assessed using modified World Health Organization [WHO] criteria [primary end point]); overall response rates (ORRs) and complete response $(\mathrm{CR})$ rates were also higher compared with GM-CSF in patients with unresectable stage IIIB-IVM1c melanoma (Table 2). ${ }^{19,28,29}$ Notably, responses to talimogene laherparepvec occurred in both injected and uninjected lesions in this study, supporting a potential systemic immune effect. Overall, 64\% of injected lesions, 34\% of uninjected non-visceral lesions, and $15 \%$ of uninjected visceral lesions decreased in size by $\geq 50 \% .{ }^{30}$ Efficacy was most pronounced in patients with melanoma that was regionally or distantly metastatic, with no visceral disease (ie, stage IIIB, IIIC, or IVM1a; ${ }^{29}$ Table 2). ${ }^{28}$ As seen in the intent-to-treat population, the DRR $(25.2 \%$ vs $1.2 \% ; P<0.0001$ [descriptive] ) and ORR (40.5\% vs $2.3 \% ; P<0.0001$ [descriptive]) were higher with talimogene laherparepvec compared with GM-CSF in patients with stage IIIB, IIIC, and IVM1a melanoma. ${ }^{29}$

Due to its unique mechanism of action and favorable toxicity profile, talimogene laherparepvec also has the potential to be combined with other therapies; trials are ongoing. ${ }^{18}$ Initial results for this agent in a Phase $\mathrm{Ib} / \mathrm{II}$ combination with ipilimumab (NCT01740297) (1,32 $^{3}$ or a Phase Ib/III combination with pembrolizumab (NCT02263508) 33 $^{33}$ in patients with advanced melanoma are promising. Furthermore, a Phase II trial (NCT02211131) is ongoing assessing the efficacy of 


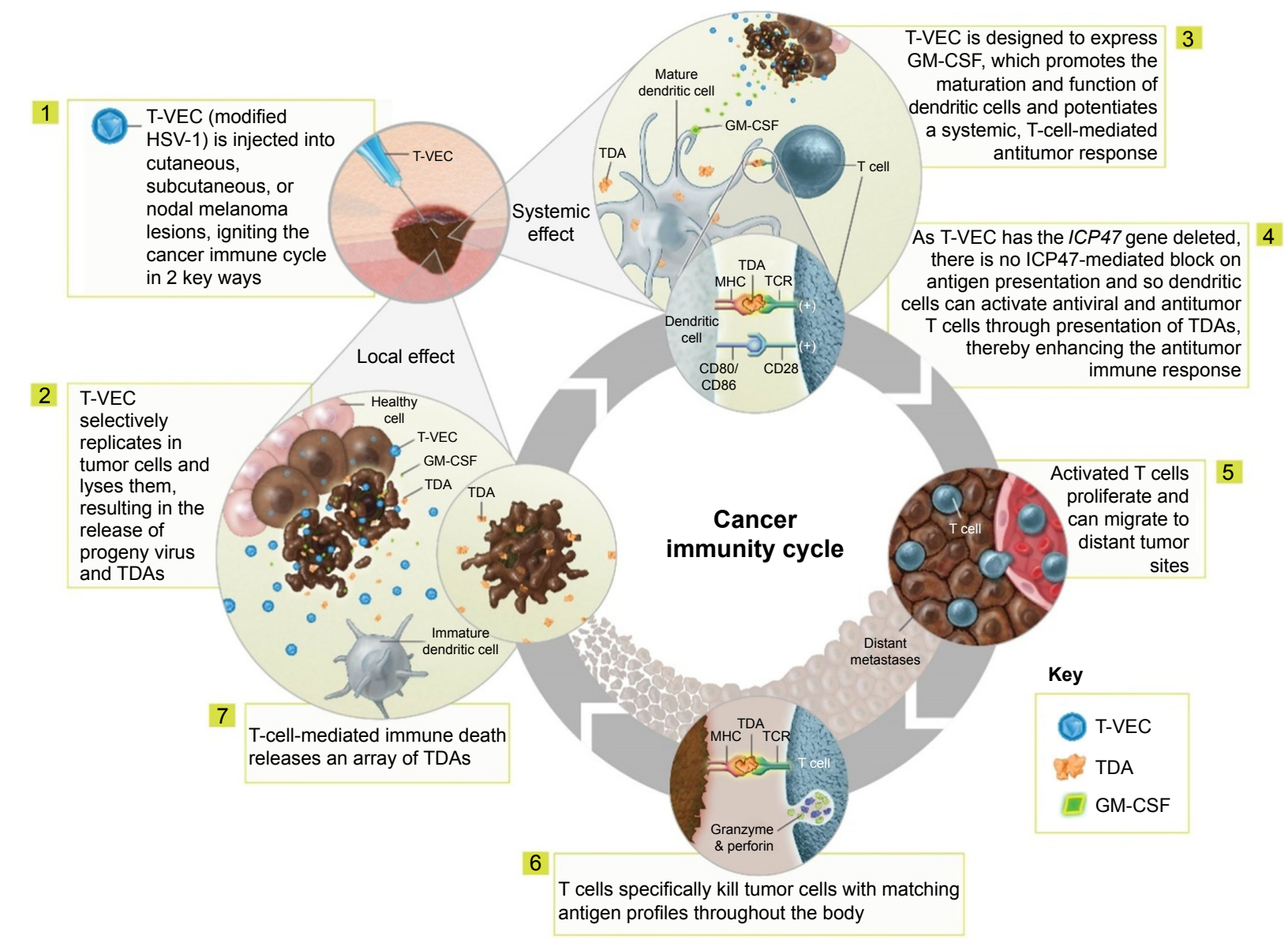

Figure I Proposed mechanism of action of talimogene laherparepvec. Copyright of Amgen Inc., reproduced with permission.

Abbreviations: GM-CSF, granulocyte-macrophage colony-stimulating factor; HSV-I, herpes simplex virus-I; MHC, major histocompatibility complex; TCR, T cell receptor; TDAs, tumor-derived antigens; T-VEC, talimogene laherparepvec.

talimogene laherparepvec as a neoadjuvant treatment in patients with resectable melanoma. Additional trials are evaluating this agent in other tumor types. For instance, a Phase I trial (NCT02509507) is in progress assessing the safety and efficacy of talimogene laherparepvec in patients with injectable tumor lesions in the liver (hepatocellular carcinoma or liver metastases from a variety of solid tumors). ${ }^{18}$ A Phase Ib/III (NCT02626000) trial is also underway evaluating talimogene

Table 2 Summary of key efficacy data from OPTiM

\begin{tabular}{|c|c|c|c|c|}
\hline & \multicolumn{2}{|c|}{ ITT (stage IIIB-IVMIc) } & \multicolumn{2}{|c|}{$\underline{\text { Stage IIIB-IVMI a subset }}{ }^{\mathrm{a}}$} \\
\hline & T-VEC $(n=295)$ & GM-CSF $(n=|4|)$ & T-VEC $(n=163)$ & GM-CSF $(n=86)$ \\
\hline Durable response rate, $\mathrm{n}(\%)$ & $48(16.3)$ & $3(2.1)$ & $4 \mid(25.2)$ & $\mathrm{I}(\mathrm{I} .2)$ \\
\hline Treatment difference, \% (95\% Cl) & 14.1 (9.3-19.0) & & $24.0(|7.0-3| .0)$ & \\
\hline$P$-value & $<0.0001$ & & $<0.000 \mathrm{I}^{\mathrm{b}}$ & \\
\hline \multicolumn{5}{|l|}{ Best response, n (\%) } \\
\hline Complete response & $32(10.8)$ & I (0.7) & $27(16.6)$ & $0(0.0)$ \\
\hline Partial response & $46(15.6)$ & $7(5.0)$ & $39(23.9)$ & $2(2.3)$ \\
\hline Objective response rate, $\%(95 \% \mathrm{Cl})$ & $26.4(2|.4-3| .5)$ & $5.7(1.9-9.5)$ & $40.5(32.9-48.4)$ & $2.3(0.3-8.1)$ \\
\hline$P$-value & $<0.000 \mathrm{I}^{\mathrm{b}}$ & & $<0.000 \mathrm{I}^{\mathrm{b}}$ & \\
\hline Overall survival, median - months $(95 \% \mathrm{Cl})$ & $23.3(19.5-29.6)$ & $18.9(16.0-23.7)$ & $4 I . I(30.6-N R)$ & $21.5(17.4-29.6)$ \\
\hline $\mathrm{HR}(95 \% \mathrm{Cl})$ & $0.79(0.62-1.00)$ & & $0.57(0.40-0.80)$ & \\
\hline$P$-value & $0.05 \mathrm{I}$ & & $<0.00 \mathrm{I}^{\mathrm{b}}$ & \\
\hline
\end{tabular}

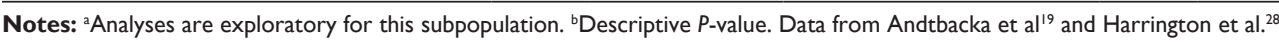

Abbreviations: $\mathrm{Cl}$, confidence interval; GM-CSF, granulocyte-macrophage colony-stimulating factor; HR, hazard ratio; ITT, intent-to-treat; NR, not reached; OPTiM, Oncovex (GM-CSF) Pivotal Trial in Melanoma; T-VEC, talimogene laherparepvec. 
laherparepvec in combination with pembrolizumab in patients with recurrent or metastatic squamous cell carcinoma of the head and neck.

The aim of this review is to provide practical information on the handling, storage, and administration procedures for talimogene laherparepvec in Europe, in line with the European and other applicable summaries of product characteristics (SmPCs). ${ }^{22,34}$

\section{Practical considerations for talimogene laherparepvec handling and administration}

Talimogene laherparepvec is a recently approved, genetically modified, virus therapy, and its handling requires special attention due to its deep freeze, cold-chain requirements and its potential for viral shedding, as well as the direct intralesional administration. A summary of the various procedures that need to be considered in relation to talimogene laherparepvec handling and administration is shown in Figure 2. Nonetheless, the regulatory environment with respect to genetically modified organisms (GMOs) has changed in recent years with regulations becoming less stringent since the initiation of the early Phase I/II studies of talimogene laherparepvec. For example, 10 years ago in the UK, there was a requirement for talimogene laherparepvec to be administered in negative-pressure, gene therapy side rooms, whereas now, it can be given routinely in an outpatient clinic/medical day unit setting (author personal experience).

\section{Transportation and storage}

Talimogene laherparepvec is provided in the form of singleuse 1-mL vials, which are color-coded depending on the

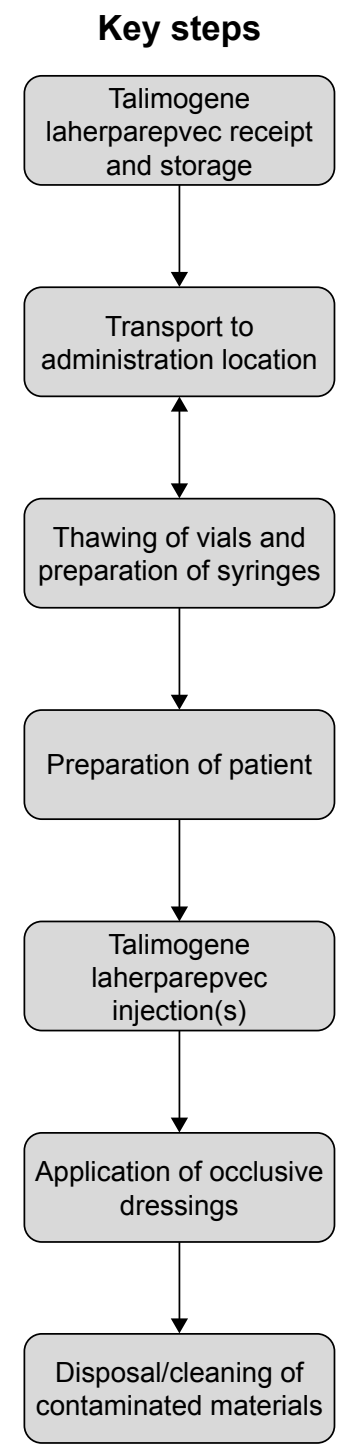

\section{Key considerations}

- Store vials at $-90^{\circ} \mathrm{C}$ to $-70^{\circ} \mathrm{C}$, protected from light in their original cartons

- Transport at $-90^{\circ} \mathrm{C}$ to $-70^{\circ} \mathrm{C}$ to administration location (eg, ward, pharmacy, clinic)

- Alternatively, talimogene laherparepvec may be thawed and syringes prepared at the storage location then transported at $2^{\circ} \mathrm{C}-8^{\circ} \mathrm{C}$ to the location of injection

- Thaw at room temperature

- If not used immediately, talimogene laherparepvec may be stored at $2^{\circ} \mathrm{C}-8^{\circ} \mathrm{C}$ (per local approved stability durations)

- Perform ultrasound (if needed), disinfect injection site and apply anesthetic patches

- Inject talimogene laherparepvec intralesionally along multiple tracks until completely/evenly dispersed

- Use a new needle each time a needle is completely removed from a lesion and for each different lesion

- Dose 1: $\leq 4 \mathrm{~mL} 10^{6} \mathrm{PFU} / \mathrm{mL}$

- Dose 2: 3 weeks later; $\leq 4 \mathrm{~mL} 10^{8} \mathrm{PFU} / \mathrm{mL}$

- Subsequent doses: Q2W; $\leq 4 \mathrm{~mL} 10^{8} \mathrm{PFU} / \mathrm{mL}$

- Apply pressure to injection site with sterile gauze, swab site with alcohol, and cover with an absorbent pad and dressing

- Dispose of needles, syringes, and other potentially contaminated materials according to local procedures; clean up spills using a virucidal agent

Figure 2 Overview of the talimogene laherparepvec handling and administration process.

Abbreviations: PFU, plaque-forming units; Q2W, once every 2 weeks. 
concentration of virus contained within; vials with light green caps contain $10^{6}$ plaque-forming units $(\mathrm{PFU}) / \mathrm{mL}$, whereas the vials with blue caps contain $10^{8} \mathrm{PFU} / \mathrm{mL} .^{22}$ The units used for quantifying this agent are different from many other anticancer therapies because it is an oncolytic virus and hence produces regions of cell destruction within a cell culture (viral "plaques") when it replicates and spreads. PFU is a measure of the number of virus particles capable of forming plaques per unit volume (ie, $\mathrm{mL}$ ). Talimogene laherparepvec is classified as an advanced therapy medicinal product (ATMP) by the European Medicines Agency (EMA), and so, a system that permits the complete traceability of the patient and product is essential. ${ }^{35}$ To permit linkage of each talimogene laherparepvec batch to the patient who received it and vice versa, a record with sufficient details is required.

At the time of writing, the recommendations for transporting, storing, and preparing talimogene laherparepvec are summarized as follows; however, health care professionals (HCPs) are advised to regularly check the talimogene laherparepvec (IMLYGIC ${ }^{\circledR}$ ) SmPC for current recommendations. ${ }^{22,34}$ The vials need to be transported, distributed, and stored frozen at a temperature of $-90^{\circ} \mathrm{C}$ to $-70^{\circ} \mathrm{C}$, protected from light in their original cartons. The unopened vials have a shelf-life of up to 4 years. A hospitalsupplied spill kit should be transported alongside the vials or, alternatively, spill kits should be available throughout the hospital site. Talimogene laherparepvec is delivered on dry ice in a time-sensitive storage container, which will maintain the correct temperature for up to 96 hours from the time the container was sealed for shipment (the time the container will expire is printed on the exterior of the package). This container may include a temperature probe that monitors the temperature throughout the entire delivery process. If the temperature logger is "alarmed" (ie, shows a temperature excursion), the product should be quarantined until the manufacturer has confirmed whether the product is still usable. Talimogene laherparepvec can either be left in the container (for up to 96 hours) until it is used, or the product can be removed and placed in a freezer at a temperature of $-90^{\circ} \mathrm{C}$ to $-70^{\circ} \mathrm{C} .^{22}$ While frozen, this agent must not be exposed to ambient temperature for longer than 60 seconds. Therefore, any transfer to a freezer must be performed within this timeframe. Talimogene laherparepvec can potentially be stored, prepared, and administered in various locations at different centers (eg, pharmacy, clinic, or on the ward), depending on local requirements. For example, depending on local standard operating procedures (SOPs), talimogene laherparepvec may be thawed and prepared in the pharmacy, transported to the clinic in preloaded syringes, and administered in either inpatient or outpatient settings. Alternatively, it can be thawed and drawn up by clinicians at the bedside immediately before it is administered to the patient, as is routinely done at some sites in Switzerland (author personal experience).

\section{Dosage and administration}

Ahead of thawing, the target lesion(s) should be measured to determine the volume of talimogene laherparepvec needed (the injection volume is based on the size of the target lesion; Table 3). ${ }^{22}$ Once the required total volume (up to a maximum of $4 \mathrm{~mL}$ per treatment visit) has been determined, the required number of vials should be thawed in their original cartons at room temperature $\left(20^{\circ} \mathrm{C}-25^{\circ} \mathrm{C}\right)$ until liquid (approximately 30 minutes) swirling (but not shaking) to aid thawing as needed. Once thawed, talimogene laherparepvec can be

Table 3 Talimogene laherparepvec dosing schedule, including injection volumes based on lesion size ${ }^{22}$

\begin{tabular}{|c|c|c|c|c|c|}
\hline \multirow[t]{2}{*}{$\begin{array}{l}\text { Treatment } \\
\text { visit }\end{array}$} & \multirow[t]{2}{*}{$\begin{array}{l}\text { Treatment } \\
\text { interval }\end{array}$} & \multirow{2}{*}{$\begin{array}{l}\text { Dose } \\
\text { concentration } \\
\text { (PFU/mL) }\end{array}$} & \multirow[t]{2}{*}{ Prioritization of lesions to be injected } & \multicolumn{2}{|c|}{$\begin{array}{l}\text { Injection volume based on } \\
\text { lesion size }\end{array}$} \\
\hline & & & & Lesion size $^{a}$ & Injection volume \\
\hline Initial & - & $10^{6}$ (I million) & $\begin{array}{l}\text { Inject largest lesion(s) first } \\
\text { Prioritize injection of remaining lesions based on } \\
\text { lesion size until maximum injection volume is reached }\end{array}$ & & \\
\hline Second & $\begin{array}{l}3 \text { weeks } \\
\text { after initial } \\
\text { treatment }\end{array}$ & $10^{8}$ (I00 million) & $\begin{array}{l}\text { Inject any new lesions (lesions may have developed } \\
\text { since initial treatment) } \\
\text { Prioritize injection of remaining lesions based on } \\
\text { lesion size until maximum injection volume is reached }\end{array}$ & $\begin{array}{l}>5 \mathrm{~cm} \\
>2.5-5 \mathrm{~cm} \\
>1.5-2.5 \mathrm{~cm} \\
>0.5-1.5 \mathrm{~cm}\end{array}$ & $\begin{array}{l}\text { Up to } 4 \mathrm{~mL} \\
\text { Up to } 2 \mathrm{~mL} \\
\text { Up to } 1 \mathrm{~mL} \\
\text { Up to } 0.5 \mathrm{~mL}\end{array}$ \\
\hline $\begin{array}{l}\text { All } \\
\text { subsequent } \\
\text { visits }^{b}\end{array}$ & $\begin{array}{l}2 \text { weeks after } \\
\text { previous } \\
\text { treatment }\end{array}$ & $10^{8}$ (100 million $)$ & $\begin{array}{l}\text { Inject any new lesions (lesions may have developed } \\
\text { since initial treatment) } \\
\text { Prioritize injection of remaining lesions based on } \\
\text { lesion size until maximum injection volume is reached }\end{array}$ & $\leq 0.5 \mathrm{~cm}$ & Up to $0.1 \mathrm{~mL}$ \\
\hline
\end{tabular}

Notes: aLongest diameter. 'Including reinitiation of treatment.

Abbreviation: PFU, plaque-forming units. 
Table 4 Maximum storage times for talimogene laherparepvec ${ }^{22}$

\begin{tabular}{|c|c|c|}
\hline \multirow[t]{3}{*}{$\begin{array}{l}\text { Storage } \\
\text { temperature }\end{array}$} & \multicolumn{2}{|c|}{$\begin{array}{l}\text { Maximum storage time for thawed } \\
\text { talimogene laherparepvec in syringe }\end{array}$} \\
\hline & $10^{6}$ (1 million) & $10^{8}(100$ million $)$ \\
\hline & PFU/mL & PFU/mL \\
\hline $2^{\circ} \mathrm{C}$ to $8^{\circ} \mathrm{C}$ & 8 hours & 16 hours \\
\hline Up to $25^{\circ} \mathrm{C}$ & 2.5 hours & 4 hours \\
\hline \multirow[t]{3}{*}{$\begin{array}{l}\text { Storage } \\
\text { temperature }\end{array}$} & \multicolumn{2}{|c|}{$\begin{array}{l}\text { Maximum cumulative storage time }{ }^{\mathrm{a}} \text { for } \\
\text { thawed talimogene laherparepvec }\end{array}$} \\
\hline & $10^{6}$ (I million) & $10^{8}(100$ million $)$ \\
\hline & $\mathrm{PFU} / \mathrm{mL}$ & PFU/mL \\
\hline $2^{\circ} \mathrm{C}$ to $8^{\circ} \mathrm{C}$ & 31 hours & 6 weeks ( 42 days) \\
\hline Up to $25^{\circ} \mathrm{C}$ & 17 hours & 85 hours \\
\hline
\end{tabular}

Note: ${ }^{\text {an }}$ vial plus storage time in syringe.

Abbreviation: PFU, plaque-forming units.

stored in its original vial or in a syringe. According to the current guidance, the maximum storage times for this agent in the refrigerator $\left(2^{\circ} \mathrm{C}-8^{\circ} \mathrm{C}\right)$ or at room temperature (up to $25^{\circ} \mathrm{C}$ ) are shown in Table $4.22,34$ Any thawed talimogene laherparepvec that has not been used after these storage times must be disposed of in accordance with local institutional guidelines/procedures for disposal of biohazard materials (described in the "Disposal and accidental spillage and exposure" section).

To permit seroconversion of HSV-1-negative patients (occurs after approximately $3-4$ weeks $^{36}$ ), the recommended initial talimogene laherparepvec dose is up to $4 \mathrm{~mL}$ at a concentration of $10^{6} \mathrm{PFU} / \mathrm{mL}$ (as dose-limiting local reactions occurred in seronegative patients at $10^{7} \mathrm{PFU} / \mathrm{mL}$ ) (Table 3$) .^{22}$ Successive doses should be up to $4 \mathrm{~mL}$ at a concentration of $10^{8} \mathrm{PFU} / \mathrm{mL}$. The second talimogene laherparepvec dose is given 3 weeks after the initial dose and subsequently administered every 2 weeks. Talimogene laherparepvec should be administered by intralesional injection into cutaneous, subcutaneous, and/or nodal lesions that are visible, palpable, or detectable by ultrasound. Talimogene laherparepvec should only be administered by direct intralesional injection - it cannot be administered intravenously. It is also not approved for direct injection into visceral metastases. When necrosis is present in larger lesions, injection of the lesion border should be considered to facilitate injection of viable tumor cells. As the total injection volume should not exceed $4 \mathrm{~mL}$, it may not be possible to inject all lesions at each treatment visit or over the course of the treatment.

Disposable protective specialist infection control gowns, safety glasses or face shields, and gloves should be worn while preparing and/or administering talimogene laherparepvec. Staff handling talimogene laherparepvec should cover any exposed wounds before the injection and avoid any contact with skin, mucosa, and eyes. The cap of the vial should be swabbed with alcohol before inserting the needle that is used to draw up the desired volume into a sterile syringe. The aim is to reach the entire lesion area using the smallest-gauge needle and with as few punctures of the skin as possible; where injection volumes are small, small-unit syringes (eg, $0.5 \mathrm{~mL}$ ) may provide improved injection control. In Switzerland, 25-gauge needles are routinely used for injecting subcutaneous melanomas, whereas 25-mm-long, 24-gauge needles are used to inject lymph node lesions. It may be beneficial to use a screw-on rather than push-on needle to reduce the likelihood of detachment during the injection process (as a relatively high pressure may be generated, eg, in fibrotic/scirrhous lesions) (author personal experience). A note should be taken of the total volume withdrawn. The injection site may be pretreated with a topical anesthetic agent or an injectable local anesthetic; however, a local anesthetic must not be injected directly into the lesion. The anesthetic should also not be mixed together with talimogene laherparepvec in the same syringe. The area should be swabbed with alcohol and allowed to dry ahead of administering talimogene laherparepvec.

Using a single insertion point, talimogene laherparepvec should be injected and redirected along multiple tracks as far as the radial reach of the needle allows to achieve complete dispersion within the lesion (Figure 3). Multiple insertion points can be used if a lesion is larger than the radial reach of the needle. The needle should always be withdrawn from the skin slowly (perhaps even allowing a period of 15-30 seconds from the end of injection before initiating needle withdrawal), to minimize the risk of leakage of injectate back through the puncture site. Any time the needle is completely withdrawn from a lesion or a different lesion is injected, a new needle should be used. An animation and video of the injection process are also available at https://www.imlygic.eu/dosing-administration and http:// www.imlygic.com/\#resources, respectively. Following administration, the injection site should be covered with sterile gauze, and pressure applied for at least 30 seconds before swabbing the area with alcohol. Gloves should be changed prior to covering the injected lesion with an absorbent pad and a dry occlusive dressing. Alternatively, the HCP can initially wear two pairs of gloves and remove one pair postinjection, ahead of applying the dressings. In many institutions, dressings are applied by nurses who at the same time instruct the patient as to how this should be done. 
A

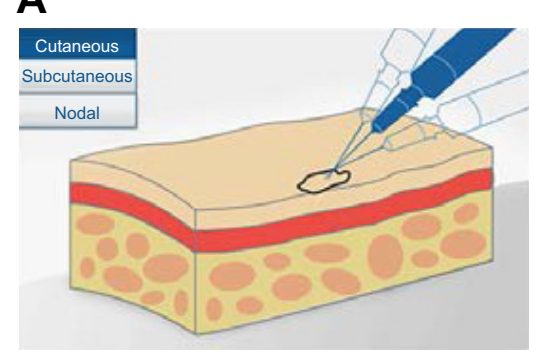

B

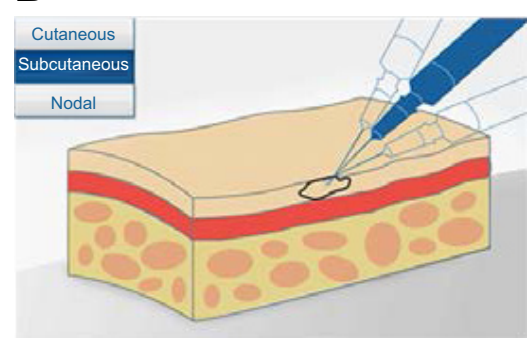

C

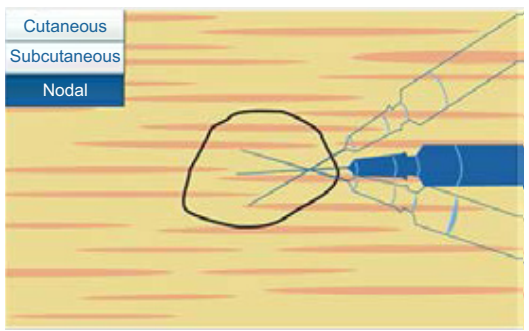

Figure 3 Diagram showing intralesional injection of talimogene laherparepvec into (A) cutaneous, (B) subcutaneous, and (C) nodal lesions. Copyright of Amgen Inc., reproduced with permission. ${ }^{22}$

Notes: Using a single injection point, talimogene laherparepvec should be injected and redirected along multiple tracks as far as the radial reach of the needle allows to achieve complete and even dispersion within the lesion. The needle should be withdrawn slowly to avoid leakage.

The patient should be advised to keep the dressings in place for at least 8 days following each injection, or longer if the injection site is oozing or weeping. Dressings should be replaced if they fall off (and reapplied as advised by their HCP), and hands should be washed afterwards.

In the case of ultrasound-guided injection, some centers use a disposable bag (an ultrasound probe cover) over the scanner to avoid contamination. This can then be disposed of along with any other material that may have come into contact with talimogene laherparepvec.

Talimogene laherparepvec is contraindicated in patients who are severely immunocompromised (eg, those with severe congenital or acquired immune deficiency). HCPs who are immunocompromised or pregnant should not prepare or administer talimogene laherparepvec and should not come into direct contact with the injection sites, dressings, or body fluids of treated patients.

\section{Disposal and accidental spillage and exposure}

Local institutional guidelines should be followed for waste disposal and accidental spills. ${ }^{22}$ All materials that have come into contact with talimogene laherparepvec (eg, vials, syringes, needles, gauze, etc) should also be disposed of in accordance with local institutional procedures. In the clinic, potentially contaminated dressings or cleaning materials should be placed in a sealed plastic bag and disposed of in accordance with local guidelines. For example, based on the author's experience in the UK, all potentially contaminated material is disposed of in a gene therapy waste disposal box, and the contents are subsequently autoclaved. Similarly, in Switzerland, all materials that have come into contact with talimogene laherparepvec are disposed of in special biohazard/biosafety bags, which then go directly for autoclaving. All talimogene laherparepvec spillages should be cleaned up using absorbent materials along with a virucidal agent. Talimogene laherparepvec is susceptible to common disinfectants such as $2.5 \%$ bleach, $70 \%$ isopropyl alcohol, or $0.8 \%$ vesphene, ${ }^{37}$ as well as commercial agents like Virkon ${ }^{\mathrm{TM}}$ (LANXESS, Cologne, Germany) and Trigene ${ }^{\circledR}$ (MediChem International Ltd, Sevenoaks, UK) (author personal experience). In the event of accidental exposure (eg, splashback to the eyes or mucous membranes), the area should be flushed with clean water for at least 15 minutes. If accidental needle stick injury or exposure of broken skin occurs, the area should be cleaned thoroughly with soap and water and/or disinfectant. If a person who is accidentally exposed to talimogene laherparepvec develops suspected herpetic lesions, it is at the discretion of the treating physician whether to take samples or swabs and send these to a central testing center to undergo polymerase chain reaction (PCR) testing for talimogene laherparepvec DNA. This test is funded by the manufacturer and aims to determine whether the infection is due to wild-type herpes virus or talimogene laherparepvec. As of April 28, 2015, there had been four reports of accidental exposure (three needlestick injuries and one splashback to the eye) in three HCPs during a total of 4100 treatment visits (https://www.fda.gov/downloads/ AdvisoryCommittees/CommitteesMeetingMaterials/ BloodVaccinesandOtherBiologics/CellularTissueandGe neTherapiesAdvisoryCommittee/UCM444715.pdf). The HCP experiencing splashback to the eye was asymptomatic and required no further treatment. One of the HCPs experiencing a needlestick injury was also asymptomatic but was treated with an antiviral agent, and the second HCP experienced two needlestick injuries; they developed a herpetic whitlow following the first incident that resolved after acyclovir administration but had no symptoms after the second incident. The remaining needlestick injury occurred in the preclinical setting. HCPs are asked to report any 
suspected adverse reactions (including suspected herpetic events in HCPs, patients, and their close contacts), as per their usual procedures.

\section{Precautions and considerations during patient follow-up}

Encouragingly, data from both completed and ongoing Phase I/II talimogene laherparepvec studies suggest that the incidence of viral shedding is rare, with a low frequency of virus detectable in swabs from the injection site $27,38,39$ and no positive swab results obtained from the exterior of dressings. ${ }^{27}$ Viral shedding evaluations also suggest that viral excretion to urine or feces is very low (http:/Www.ema. europa.eu/docs/en GB/document library/EPAR - Public assessment report/human/002771/WC500201082.pdf), and no specific measures or precautions are required with regard to the use of bathroom facilities. An ongoing Phase II trial (NCT02014441) in patients with stage IIIB-IVM1c melanoma is further investigating the biodistribution and potential for shedding with this agent. Recently reported interim results from 30 patients treated in this study also indicate a low potential for transmission of talimogene laherparepvec from treated individuals to HCPs and close contacts, when this agent is administered as indicated. ${ }^{39}$ Viral DNA was occasionally detected on the exterior of the occlusive dressing; in contrast, no live virus was found, indicating that the occlusive dressing forms an effective barrier for potential transmission from lesions injected with talimogene laherparepvec. Nevertheless, after administration, patients should be advised to avoid touching or scratching the injection site as this could lead to inadvertent transfer of talimogene laherparepvec to other parts of their body or to their close contacts. ${ }^{22}$ It is also recommended that while on treatment and within 30 days after treatment with talimogene laherparepvec, patients should use a condom during sexual contact to prevent possible virus transmission, although sexual transmission during or after treatment has not been documented to date. There are no restrictions on the patient in terms of advice to avoid public spaces, such as restaurants or bathrooms. Key points to discuss with patients regarding how to avoid spreading talimogene laherparepvec are summarized in Figure 4. As a HSV-1-based agent, talimogene laherparepvec is susceptible to soap and common disinfectants, and so, regular handwashing is recommended, particularly after any contact with the injection site or contaminated dressings.

As with other immunotherapies, patients on talimogene laherparepvec may experience an increase in the size of existing tumor lesions (so-called pseudo-progression) or the appearance of new lesions (ie, progression) prior to achieving a response. ${ }^{30}$ Therefore, immune-related response criteria (eg, irRC $)^{40}$ or immune-related Response Evaluation Criteria In Solid Tumors (RECIST) ${ }^{41}$ could be used to monitor

- Avoid direct contact between injection sites/body fluids and close contacts for the duration of talimogene laherparepvec treatment and until 30 days after the last dose

- To minimize risk of exposure of blood and body fluids to close contacts, the following activities should be avoided:

- Sexual intercourse without a latex condom

- Kissing if either party has an open mouth sore

- Common usage of cutlery, crockery, and drinking vessels

- Common usage of injection needles, razor blades, and tooth brushes

- Avoid touching or scratching the injection sites

- Keep injection sites covered with airtight and watertight dressings for at least 8 days following each injection

- If the injection site is weeping or oozing, keep the dressing on until this stops. Apply dressing as instructed by your health care professional. If the dressing comes loose or falls off, replace it straight away with a clean dressing

- Place all used dressings and cleaning materials in a sealed plastic bag, and throw them away in household waste, to keep household contacts from directly touching them

- Wash hands with soap and water after any contact with the injection site or contaminated dressings

- During talimogene laherparepvec treatment, there are no restrictions/special precautions regarding visiting public places, eg, restaurants, bathrooms, etc

Figure 4 Key points for avoiding spreading talimogene laherparepvec - advice for patients. 
Table 5 Evaluation of response by immune-related response criteria (irRC), World Health Organization (WHO) criteria, and Response Evaluation Criteria In Solid Tumors (RECIST)

\begin{tabular}{|c|c|c|c|}
\hline & $\operatorname{irRC}^{40}$ & $\mathrm{WHO}^{42}$ & RECIST $^{43}$ \\
\hline Method & $\begin{array}{l}\text { Sum of products of the two longest diameters in } \\
\text { perpendicular dimensions (bidimensional) }\end{array}$ & $\begin{array}{l}\text { Sum of products of the two } \\
\text { longest diameters in perpendicular } \\
\text { dimensions (bidimensional) }\end{array}$ & $\begin{array}{l}\text { Sum of longest diameters } \\
\text { (unidimensional) }\end{array}$ \\
\hline Number of measured lesions & $\begin{array}{l}\text { Index lesions (maximum } 5 \text { per organ; } 10 \text { visceral } \\
\text { lesions and } 5 \text { cutaneous lesions) plus new, } \\
\text { measurable lesions ( } \geq 5 \times 5 \mathrm{~mm} \text {; up to } 5 \text { new } \\
\text { lesions per organ; } 5 \text { new cutaneous lesions and } \\
10 \text { visceral lesions) }\end{array}$ & All lesions & $\begin{array}{l}\text { Target lesions (maximum } \\
2 \text { per organ; } 5 \text { in total) }\end{array}$ \\
\hline New, measurable lesions & $\geq 5 \times 5 \mathrm{~mm}$; incorporated into tumor burden & $\geq 5 \times 5 \mathrm{~mm}$; always represent PD & $\geq 10 \mathrm{~mm}$; always represent PD \\
\hline New non-measurable lesions & $<5 \times 5 \mathrm{~mm}$; do not define PD (but precludes CR) & $<5 \times 5 \mathrm{~mm}$; always represent PD & $<10 \mathrm{~mm}$; always represent PD \\
\hline Non-index lesions & Contribute to defining CR & $\begin{array}{l}\text { Changes contribute to defining } \\
\text { best overall response of } C R, P R \text {, } \\
S D \text {, and PD }\end{array}$ & $\begin{array}{l}\text { Changes contribute to defining } \\
\text { best overall response of } C R \text {, } \\
\text { PR, SD, and PD }\end{array}$ \\
\hline \multicolumn{4}{|l|}{ Response } \\
\hline CR & $\begin{array}{l}\text { Disappearance of all lesions in two consecutive } \\
\text { observations not less than } 4 \text { weeks apart }\end{array}$ & $\begin{array}{l}\text { Disappearance of all known } \\
\text { disease, confirmed at } 4 \text { weeks }\end{array}$ & $\begin{array}{l}\text { Disappearance of all known } \\
\text { disease, confirmed at } 4 \text { weeks }\end{array}$ \\
\hline PR & $\begin{array}{l}\geq 50 \% \text { decrease in tumor burden compared with } \\
\text { baseline in two consecutive observations not } \\
\text { less than } 4 \text { weeks apart }\end{array}$ & $\begin{array}{l}\geq 50 \% \text { decrease, confirmed at } \\
4 \text { weeks }\end{array}$ & $\begin{array}{l}\geq 30 \% \text { decrease, confirmed at } \\
4 \text { weeks }\end{array}$ \\
\hline SD & Neither PR nor PD criteria met & Neither PR nor PD criteria met & Neither PR nor PD criteria met \\
\hline PD & $\begin{array}{l}\geq 25 \% \text { increase in tumor burden compared } \\
\text { with nadir (at any single time point) in two } \\
\text { consecutive observations at least } 4 \text { weeks apart }\end{array}$ & $\begin{array}{l}\geq 25 \% \text { increase, no } C R, P R \text {, or } \\
\text { SD documented before increased } \\
\text { disease, new lesion(s), } \geq 25 \% \\
\text { increase in I lesion }\end{array}$ & $\begin{array}{l}\geq 20 \% \text { increase, no CR, PR, } \\
\text { or SD documented before } \\
\text { increased disease, new lesion(s) }\end{array}$ \\
\hline
\end{tabular}

Abbreviations: $C R$, complete response; PD, progressive disease; PR, partial response; SD, stable disease.

treatment response, as these take into account the patterns of response observed with immunotherapies, and thereby provide a better assessment of their activity than other commonly used criteria such as WHO criteria or RECIST (Table 5). ${ }^{40,42,43}$ For instance, with irRC, ${ }^{40}$ the occurrence of new lesions is not classified as progression so long as these comprise less than a $25 \%$ increase in tumor burden compared with nadir, and are confirmed at two consecutive observations at least 4 weeks apart. Talimogene laherparepvec treatment should be continued for $\geq 6$ months, unless no injectable tumor lesions remain or the treating physician thinks that the patient is not benefitting or that another treatment is required. Treatment with talimogene laherparepvec may also be reinitiated if new lesions appear following a CR.

In the Phase III OPTiM trial, talimogene laherparepvec was well tolerated. Nevertheless, side effects can occur, with the most commonly reported (affecting $\geq 25 \%$ of patients) being fatigue $(50 \%)$, chills $(49 \%)$, pyrexia (43\%), nausea $(36 \%)$, influenza-like illness (31\%), and injection-site pain (28\%). These adverse events (AEs) may be encountered more frequently during early treatment cycles. For example, influenza-like symptoms were more frequent during the period of the first six talimogene laherparepvec treatments, particularly in those who were HSV-1 seronegative at baseline. ${ }^{19}$ Such symptoms were mostly mild to moderate and generally resolved within 72 hours. If necessary, patients can receive antipyretic medications, such as paracetamol/ acetaminophen, and nonsteroidal anti-inflammatory drugs such as naproxen, diclofenac, or ibuprofen. Overall, $98 \%$ of AEs reported during talimogene laherparepvec treatment were mild or moderate in severity. The most common grade 3 or higher AE was cellulitis ( $2 \%),{ }^{19}$ and therefore, careful wound care and infection precautions are recommended, particularly if tumor necrosis results in open wounds. Immune-related AEs such as vasculitis, pneumonitis, and vitiligo have also been noted during talimogene laherparepvec treatment, all events being nonserious and occurring in $\leq 7 \%$ of patients. ${ }^{19,29}$

Herpetic infection has been reported in some patients, ${ }^{22,44}$ likely due to reactivation of latent wild-type HSV-1. There is also a potential for reactivation of talimogene laherparepvec, although the deletion of the neurovirulence factor, ICP 34.5 , reduces the likelihood of this event to occur. If signs or symptoms of herpes infection are observed, the affected individual should contact a HCP who may decide to evaluate the presence of DNA from talimogene laherparepvec via central PCR testing. If treatment is needed, talimogene laherparepvec is 
sensitive to commonly used antiviral/antiherpetic agents like acyclovir (an antimetabolite of thymidine kinase), as the gene for thymidine kinase in this GMO is unchanged.

As part of the controlled distribution program requested by the EMA, which is also followed by Swissmedic, regulatoryapproved information brochures designed specifically for physicians and patients/their close contacts are provided to inform them about the potential risks associated with talimogene laherparepvec treatment, as well as handling instructions and protective measures. Further information on the controlled distribution program (including training) is provided in the "Discussion" section.

\section{Patient case studies}

Examples of the use of standard and ultrasound-guided administration of talimogene laherparepvec in two patients undergoing treatment are summarized in Figure 5. As patient 1 had cutaneous lesions that were visible on clinical

\section{Case presentation and history}

- 82-year-old female diagnosed with melanoma in lower right leg in November 2014

- Breslow thickness: $1.85 \mathrm{~mm}$

- Clark level IV

- Ulceration

- BRAF wild-type

- Comorbidities of hypertension, venous insufficiency of lower extremities, dyslipidemia, and nephropathy

- Surgery of primary tumor

- Sentinel node biopsy not performed (patient decision)

- Metastasis in March 2015

- Cutaneous lesions in lower right leg: stage IIIC

- Entry into talimogene laherparepvec trial (NCT02366195)

\section{Standard talimogene laherparepvec administration}

- Standard administration was used as cutaneous lesions were visible on clinical examination

- Administration at week 12 (cycle 6): 4 syringes prepared containing the correct volume of drug for each lesion (index lesion 1: $1 \mathrm{~mL} ; 2: 0.5 \mathrm{~mL}$ and 3: $0.5 \mathrm{~mL}$; non-index lesion: $0.1 \mathrm{~mL}$ )
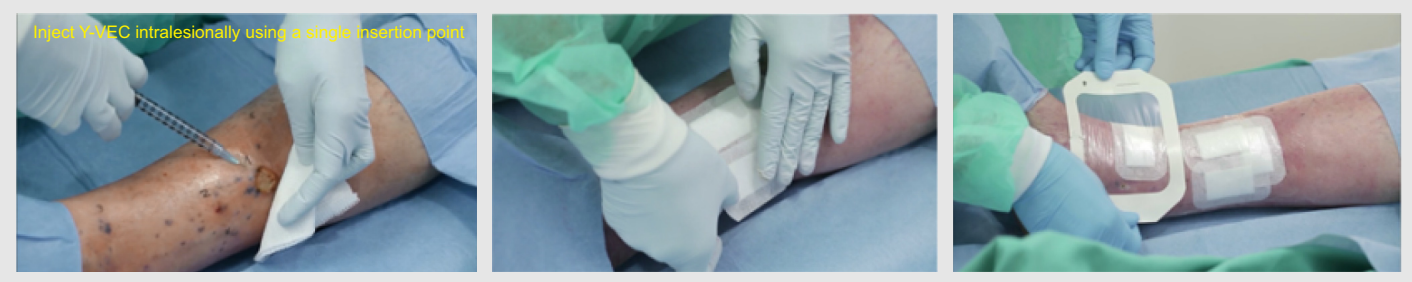

- Needle entry point outside of lesion as patient was prone to bleeding and index lesion 1 was painful and as remaining lesions were small and difficult to reach (permitting some fanning of the needle during injection)

- Absorbent pads used to absorb any leakage from the lesion during injection

- At baseline (week 0) total tumor surface area: $1,062 \mathrm{~mm}^{2}$

- At week 12 (cycle 6) total tumor surface area: $411 \mathrm{~mm}^{2}$

- Index lesion 1: $20 \times 13 \mathrm{~mm}$; $: 10 \times 4 \mathrm{~mm}$ and 3: $12 \times 8 \mathrm{~mm}$; non-index lesion: $5 \times 3 \mathrm{~mm}$

Patient follow-up

- Last talimogene laherparepvec administration was week 26 (cycle 13)

- Index lesions 1 and 2: CR

- Index lesion 3: $4 \times 3 \mathrm{~mm}$ was the only injected lesion

- At week 28, index lesion 3 biopsied

- Infiltrate containing melanophages and lymphocytes

- CR confirmed; patient still in CR as of June 2016 (response duration at last follow-up: 6 months) 


\section{Case presentation and history}

- 44-year-old male patient diagnosed with stage IIIB melanoma in the lower right leg in April 2013

- Breslow thickness: $3.20 \mathrm{~mm}$

- Clark level IV

- 4-5 mitosis $/ \mathrm{mm}^{2}$

- Ulcerated (reepithelialization)

- $\mathrm{pT} 3 \mathrm{~b}$

- Sentinel node positive (T3 N1a) and lymphadenectomy

- BRAF mutant

- February-June 2014: high-dose interferon

- July 2014: high-dose interferon treatment interrupted due to cutaneous progression (stage IIIC)

- Treatment: surgery of cutaneous metastasis, free of disease

- December 2014: appearance of 2 new lesions in subcutaneous tissue

- Treatment: surgery, no systemic disease

- May 2015: progression with 6 new lesions in subcutaneous tissue

- Entry into talimogene laherparepvec trial (NCT02366195)

\section{Ultrasound-guided talimogene laherparepvec administration}

- Administration was ultrasound-guided as subcutaneous lesions were present

- At baseline (week 0) total tumor surface area: $813 \mathrm{~mm}^{2}$

- At week 12 (cycle 6) total tumor surface area: $336 \mathrm{~mm}^{2}$

- Index lesion 1: 4x2 mm; 2: 3×3 mm; 3: $14 \times 13 \mathrm{~mm}$; : 9x6 mm; 5: 0x0 mm; 6: 9x9 mm

- Administration at week 12 (cycle 6): 4 syringes prepared containing the correct volume of drug for each lesion (index lesion 2: $0.1 \mathrm{~mL}$; $3: 0.5 \mathrm{~mL}$; $4: 0.5 \mathrm{~mL}$; $6: 0.5 \mathrm{~mL}$ [index lesion 1 \{nodal\} and $5\{\mathrm{CR}$ \}: no drug administered])

- At week 14 (cycle 7), index lesions 4 and 6 active, with the remaining 4 in CR
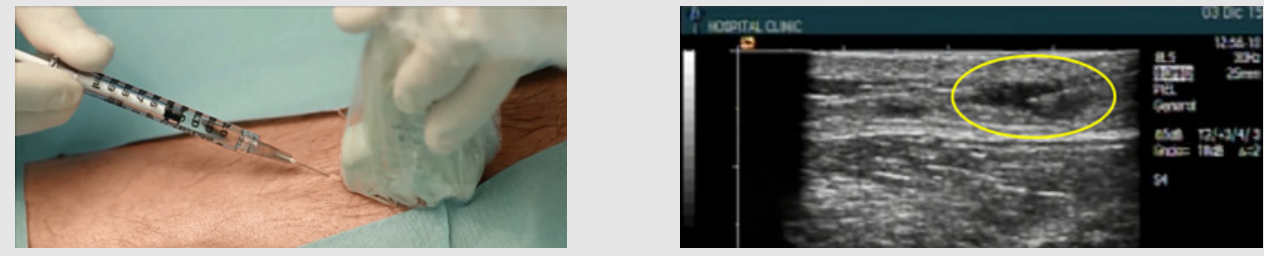

\section{Patient follow-up}

- Last talimogene laherparepvec administration was January 2016

- Index lesion 4 was the only injected lesion

- Radiological CR and talimogene laherparepvec discontinued

- Index lesion 4 was confirmed to be in CR by biopsy and was still necrotic in June 2016

- Patient still in CR as of September 2016 (response duration at last follow-up: 10 months)

Figure 5 Case studies demonstrating standard and ultrasound-guided administration of talimogene laherparepvec. The yellow oval indicates the injected lesion under ultrasound guidance. The patients provided written informed consent for the publication of the case details and any accompanying images.

Abbreviation: $\mathrm{CR}$, complete response.

examination, standard administration was used, whereas the presence of subcutaneous lesions in patient 2 required the use of ultrasound guidance. These patients received treatment during a Phase II trial evaluating the correlation between CD8+ density and response to talimogene laherparepvec in unresected melanoma (NCT02366195). At the time of talimogene laherparepvec administration, both patients had stage IIIC melanoma with multiple lesions in the lower leg. Both patients were still in CR at last follow-up (response duration at last follow-up, 6 months and 10 months, for cases 1 and 2, respectively). Further information regarding these two cases, including videos of the talimogene laherparepvec administration process, is available in Supplementary material. 


\section{Discussion}

Because of the special requirements mentioned above, and as talimogene laherparepvec is classified as an ATMP, it will initially be available in Europe only through a special controlled distribution program. This will also mean that the product supply chain will be managed to ensure that cold storage requirements are met. Initially, in Europe, distribution will be limited to qualified centers that commit to ensuring that HCPs: 1) are adequately trained to minimize the risk of side effects (such as herpetic infections) in themselves, patients, and their close contacts; 2) agree to provide their patients with specified safety and handling information; 3 ) are trained on the need for correct storage, traceability, handling, and patient follow-up, and 4) are aware of the correct process for reporting adverse drug reactions. As pharmacists are generally experienced in handling hazardous materials (eg, chemotherapy), only minor adaptations to their current practices will be needed when working with talimogene laherparepvec.

Initially, it is likely that only centers experienced in using talimogene laherparepvec or oncolytic/genetically modified viruses will be able to administer this treatment. In the future, these larger, more experienced clinical centers could potentially offer training and support to smaller centers that would like to start using this agent. This will help to ensure that SOPs are shared and any potential barriers to initiating treatment can be overcome. However, it is possible that in some countries or regions, talimogene laherparepvec administration may remain limited to larger centers.

Different specialists are likely to be involved at different stages of the handling and administration of talimogene laherparepvec depending on the capabilities of each center: for example, the treating physician (ie, a dermatologist, oncologist, dermato-oncologist, or surgeon) or nurse (in some countries) for cutaneous/subcutaneous administration of talimogene laherparepvec, pharmacists or nurses for storage/ preparation, and radiologists for ultrasound imaging of nodal lesions prior to and during talimogene laherparepvec administration. Furthermore, practice also differs between countries. For example, in the UK, melanoma treatment has historically been managed by radiation/medical oncologists, whereas elsewhere in Europe, it varies by country and site. In Germany and Austria, a dermato-oncologist is often responsible for melanoma treatment; dermato-oncologists are also involved in treatment in melanoma referral centers in France, Italy, Spain, and Switzerland, and here, they are also sometimes primarily responsible for treatment. In the US, surgeons and oncologists generally provide treatment.
As many specialists are likely to be involved at different stages of the talimogene laherparepvec handling and administration process, there is a need for good interdisciplinary collaboration when using this agent.

In Europe, within the framework of clinical research, handling procedures for infective microorganisms, including GMOs, are defined under four different biosafety levels (BSL-1-4), depending on the level of perceived risk (http://www.who.int/ihr/publications/WHO CDS CSR LYO 2004 11/en/). ${ }^{45}$ Microorganisms believed to be at no or low risk of causing disease in humans or animals and so have no special requirements for handling are classified as BSL-1, while those that can cause disease but that are unlikely to be a serious hazard to laboratory workers are classified as BSL-2. With the use of protective clothing, BSL-2 organisms can still be handled on an open bench, but a biological safety cabinet may be needed where there is the potential for aerosol formation. BSL-3 pathogens usually cause serious human or animal disease but are not readily spread between individuals, and effective prevention and treatment strategies are usually available. Such organisms should always be handled in a biological safety cabinet. The highest designation (BSL-4) is rarely used, being reserved for pathogens that usually cause serious disease in humans or animals, are readily transmitted, and for which effective treatment or preventative measures are generally not available. BSL-4 organisms can only be handled in specialized dangerous pathogen units. Before talimogene laherparepvec received its marketing authorization, each country performed its own assessment to determine the BSL level that should be used during clinical trials, and so, there are currently some differences between European countries in biosafety/ handling requirements. For example, a BSL-1 designation was used during the Phase III OPTiM clinical trial in the UK, whereas BSL-2 was used in Germany, although BSL-1 is now being used here too following a recent reclassification by the German authorities (http://apps2.bvl.bund.de/organismen/ organisms.jsf;jsessionid=ncbJnjAV3BpaqxsyMIZLVWN9. undefined). Requirements also differ in the US, and there is no reference to a BSL categorization in the US prescribing information for talimogene laherparepvec. ${ }^{21,46}$ Nonetheless, the safety data sheet for talimogene laherparepvec states that BSL-1 containment and work practices are appropriate for most research and development activities handling volumes less than $10 \mathrm{~L}$ and for medical facilities administering the product in single-dose vials. ${ }^{37}$ Where volumes greater than $10 \mathrm{~L}$ are being used (eg, in a manufacturing setting), use of large-scale BSL-2 containment and work practices is 
recommended. As part of the marketing authorization process, a full environmental risk assessment was submitted to the EMA. The Committee for Medicinal Products for Human Use concluded that the overall risk posed by talimogene laherparepvec was low. Now that marketing authorization has been granted, use of this agent in clinical practice should be in line with the guidelines included in the SmPCs (which do not refer to any particular BSL designation). ${ }^{22}$ Nonetheless, each country has its own national regulatory authority with respect to biosafety requirements (eg, http://www.ema. europa.eu/ema/index.jsp?curl=pages/medicines/general/ general_content_000155.jsp). For instance, Swissmedic, the regulatory authority in Switzerland, provided the framework for talimogene laherparepvec handling and administration, personal protective equipment, and spills/waste disposal during clinical trials in Switzerland, but then each site developed its own local process to meet these requirements. Adaptations to a national framework may also be needed at individual institutions depending on local factors such as infrastructure, staff resources, and internal/local regulatory/safety SOPs.

In summary, talimogene laherparepvec is a novel oncolytic immunotherapy that has demonstrated proven efficacy and good tolerability in patients with stage IIIB-IVM1a melanoma. In line with this, talimogene laherparepvec has been approved in Europe for the treatment of adults with unresectable melanoma that is regionally or distantly metastatic (stage IIIB, IIIC, and IVM1a) with no bone, brain, lung, or other visceral disease. ${ }^{22}$ Although its storage, handling, administration, and disposal require special attention, use in clinical trials and the commercial setting to date has shown that these can be effectively managed. Effective management may involve tailoring of processes to site-specific local factors such as infrastructure, staff resources, and institutional guidelines, as well as the development and implementation of training and straightforward SOPs.

\section{Acknowledgments}

Medical writing assistance (funded by Amgen [Europe] GmbH, Zug, Switzerland) was provided by Dawn Batty, PhD (Bioscript Medical Ltd, Macclesfield, UK). KJH acknowledges support from the ICR/RM NIHR Biomedical Research Centre.

\section{Disclosure}

$\mathrm{KJH}$ has acted as a consultant/in an advisory role for Amgen, Bristol-Myers Squibb (BMS), Genelux Corp., Lytix, Merck Serono, Merck Sharp \& Dohme (MSD), Oncolytics Biotech, Oncos Therapeutics, Pfizer, and Viralytics. OM has acted as a consultant/advisor for Amgen Inc., BMS, MSD, Novartis, and Roche, and received travel/accommodation from BMS and MSD. JM has received honoraria from Amgen Inc., BMS, MSD, Novartis, and Roche, has acted as a consultant/ advisor for Amgen Inc., BMS, MSD, Novartis, and Roche, and has received research funding for institution from BMS, GlaxoSmithKline, MSD, Novartis, and Roche. IPG is an Amgen Switzerland AG employee and owns restricted shares in Amgen. LG has acted in an advisory role for Amgen. RD has intermittent, project-focused consulting and/or advisory relationships with Amgen, BMS, MSD, Novartis, Pierre Fabre, Roche, and Takeda, outside the submitted work. ALF has no conflicts of interest to declare.

\section{References}

1. Johnson DB, Puzanov I, Kelley MC. Talimogene laherparepvec (T-VEC) for the treatment of advanced melanoma. Immunotherapy. 2015;7(6): 611-619.

2. Sloot S, Rashid OM, Zager JS. Intralesional therapy for metastatic melanoma. Expert Opin Pharmacother. 2014;15(18):2629-2639.

3. Tronnier M, MitteldorfC. Treating advanced melanoma: current insights and opportunities. Cancer Manag Res. 2014;6:349-356.

4. Agarwala SS, Neuberg D, Park Y, Kirkwood JM. Mature results of a phase III randomized trial of bacillus Calmette-Guerin (BCG) versus observation and BCG plus dacarbazine versus BCG in the adjuvant therapy of American Joint Committee on Cancer Stage I-III melanoma (E1673): a trial of the Eastern Oncology Group. Cancer. 2004;100(8):1692-1698.

5. Thompson JF, Agarwala SS, Smithers BM, et al. Phase 2 study of intralesional PV-10 in refractory metastatic melanoma. Ann Surg Oncol. 2015;22(7):2135-2142.

6. Weide B, Eigentler TK, Pflugfelder A, et al. Intralesional treatment of stage III metastatic melanoma patients with L19-IL2 results in sustained clinical and systemic immunologic responses. Cancer Immunol Res. 2014;2(7):668-678.

7. von Wussow $P, B$ lock B, Hartmann F, Deicher H. Intralesional interferonalpha therapy in advanced malignant melanoma. Cancer. 1988;61(6): 1071-1074.

8. Si Z, Hersey P, Coates AS. Clinical responses and lymphoid infiltrates in metastatic melanoma following treatment with intralesional GM-CSF. Melanoma Res. 1996;6(3):247-255.

9. Heinzerling L, Burg G, Dummer R, et al. Intratumoral injection of DNA encoding human interleukin 12 into patients with metastatic melanoma: clinical efficacy. Hum Gene Ther. 2005;16(1):35-48.

10. MacKie RM, Stewart B, Brown SM. Intralesional injection of herpes simplex virus 1716 in metastatic melanoma. Lancet. 2001;357(9255): $525-526$.

11. Watanabe D, Goshima F, Mori I, Tamada Y, Matsumoto Y, Nishiyama Y. Oncolytic virotherapy for malignant melanoma with herpes simplex virus type 1 mutant HF10. J Dermatol Sci. 2008;50(3):185-196.

12. Andtbacka RHI, Curti BD, Kaufman H, et al. Final data from CALM: a phase II study of Coxsackievirus A21 (CVA21) oncolytic virus immunotherapy in patients with advanced melanoma. J Clin Oncol. 2015; 33 Suppl:abstract 9030.

13. Urosevic M, Fujii K, Calmels B, et al. Type I IFN innate immune response to adenovirus-mediated IFN-gamma gene transfer contributes to the regression of cutaneous lymphomas. J Clin Invest. 2007;117(10): 2834-2846.

14. Heinzerling L, Kunzi V, Oberholzer PA, Kundig T, Naim H, Dummer R. Oncolytic measles virus in cutaneous T-cell lymphomas mounts antitumor immune responses in vivo and targets interferon-resistant tumor cells. Blood. 2005;106(7):2287-2294. 
15. Melcher A, Parato K, Rooney CM, Bell JC. Thunder and lightning: immunotherapy and oncolytic viruses collide. Mol Ther. 2011;19(6): 1008-1016.

16. Lichty BD, Breitbach CJ, Stojdl DF, Bell JC. Going viral with cancer immunotherapy. Nat Rev Cancer. 2014;14(8):559-567.

17. Pol JG, Rességuier J, Lichty BD. Oncolytic viruses: a step into cancer immunotherapy. Virus Adapt Treat. 2012;4:1-21.

18. Harrington KJ, Puzanov I, Hecht JR, et al. Clinical development of talimogene laherparepvec (T-VEC): a modified herpes simplex virus type-1-derived oncolytic immunotherapy. Expert Rev Anticancer Ther. 2015;15(12):1389-1403.

19. Andtbacka RH, Kaufman HL, Collichio F, et al. Talimogene laherparepvec improves durable response rate in patients with advanced melanoma. J Clin Oncol. 2015;33(25):2780-2788.

20. NICE National Institute for Health and Care Excellence. Talimogene laherparepvec for treating unresectable metastatic melanoma. Technology appraisal [TA410]. 2016. Available from: https://www.nice.org. uk/guidance/ta410. Accessed October 3, 2016.

21. IMLYGIC ${ }^{\circledR}$ (talimogene laherparepvec) [prescribing information]. Thousand Oaks, CA: Amgen Inc.; 2015.

22. IMLYGIC ${ }^{\circledR}$ (talimogene laherparepvec) [summary of product characteristics]. Breda: Amgen Europe B.V.; 2016.

23. Liu BL, Robinson M, Han ZQ, et al. ICP34.5 deleted herpes simplex virus with enhanced oncolytic, immune stimulating, and anti-tumour properties. Gene Ther. 2003;10(4):292-303.

24. Fukuhara H, Todo T. Oncolytic herpes simplex virus type 1 and host immune responses. Curr Cancer Drug Targets. 2007;7(2):149-155.

25. Hawkins LK, Lemoine NR, Kirn D. Oncolytic biotherapy: a novel therapeutic plafform. Lancet Oncol. 2002;3(1):17-26.

26. Dranoff G. GM-CSF-secreting melanoma vaccines. Oncogene. 2003; 22(20):3188-3192.

27. Harrington KJ, Hingorani M, Tanay MA, et al. Phase I/II study of oncolytic HSV GM-CSF in combination with radiotherapy and cisplatin in untreated stage III/IV squamous cell cancer of the head and neck. Clin Cancer Res. 2010;16(15):4005-4015.

28. Harrington KJ, Andtbacka FHI, Collichio F, et al. Disease characteristics, treatment outcomes and safety with talimogene laherparepvec vs GMCSF in patients with stage IIIB/C and IVM1a melanoma in OPTiM. Poster presented at: 11th European Association of Dermato Oncology (EADO) Congress and 8th World Meeting of Interdisciplinary Melanoma/Skin Cancer Centers, Marseille, France; October 28-31, 2015.

29. Harrington KJ, Andtbacka RH, Collichio F, et al. Efficacy and safety of talimogene laherparepvec versus granulocyte-macrophage colonystimulating factor (GM-CSF) in patients with stage IIIB/C and IVM1a melanoma: subanalysis of the Phase III OPTiM trial. Onco Targets Ther. 2016;9:7081-7093.

30. Andtbacka RH, Ross M, Puzanov I, et al. Patterns of clinical response with talimogene laherparepvec (T-VEC) in patients with melanoma treated in the OPTiM phase III clinical trial. Ann Surg Oncol. 2016; 23(13):4169-4177.

31. Puzanov I, Milhem MM, Minor D, et al. Talimogene laherparepvec in combination with ipilimumab in previously untreated, unresectable stage IIIB-IV melanoma. J Clin Oncol. 2016;34(22):2619-2626.

32. Chesney J, Collichio F, Andtbacka RH, et al. Interim efficacy and safety of a randomized (1:1) open-label phase 2 study of talimogene laherparepvec and ipilimumab vs ipilimumab alone in unresected, stage IIIB-IV melanoma. Ann Oncol. 2016;27 Suppl 6:379-400.

OncoTargets and Therapy

\section{Publish your work in this journal}

OncoTargets and Therapy is an international, peer-reviewed, open access journal focusing on the pathological basis of all cancers, potential targets for therapy and treatment protocols employed to improve the management of cancer patients. The journal also focuses on the impact of management programs and new therapeutic agents and protocols on
33. Long GV, Dummer R, Ribas A, et al. Efficacy analysis of MASTERKEY265 phase $1 \mathrm{~b}$ study of talimogene laherparepvec and pembrolizumab for unresected stage IIIB-IV melanoma. Poster presented at: American Society of Clinical Oncology Annual Meeting, Chicago, IL, USA; June 3-7, 2016.

34. IMLYGIC $^{\circledR}$ (talimogene laherparepvec) [prescribing information]. Zug: Amgen Switzerland AG; 2016.

35. Abdullah HA. Talimogene laherparepvec: advanced therapy medicinical product (ATMP) - a distinct risk management plan. Poster presented at: Develop Innovate Advance (DIA) meeting, Philadelphia, PA, USA; June 26-30, 2016.

36. Hu JC, Coffin RS, Davis CJ, et al. A phase I study of OncoVEXGMCSF, a second-generation oncolytic herpes simplex virus expressing granulocyte macrophage colony-stimulating factor. Clin Cancer Res. 2006;12(22):6737-6747.

37. IMLYGICTM (talimogene laherparepvec) [safety data sheet]. Thousand Oaks, CA: Amgen Inc.; 2016.

38. Senzer NN, Kaufman HL, Amatruda T, et al. Phase II clinical trial of a granulocyte-macrophage colony-stimulating factor-encoding, secondgeneration oncolytic herpesvirus in patients with unresectable metastatic melanoma. J Clin Oncol. 2009;27(34):5763-5771.

39. Amatruda T, Mehnert J, Walker J, et al. Interim analysis (IA) of a phase 2 multicenter single arm clinical trial to evaluate biodistribution and shedding of talimogene laherparepvec (T-VEC) in patients (pts) with unresected Stages IIIB-IV melanoma. Poster presented at: Society for Melanoma Research (SMR) Congress, Boston, MA, USA; November 6-9, 2016.

40. Wolchok JD, Hoos A, O’Day S, et al. Guidelines for the evaluation of immune therapy activity in solid tumors: immune-related response criteria. Clin Cancer Res. 2009;15(23):7412-7420.

41. Seymour L, Bogaerts J, Perrone A, et al; RECIST working group. iRECIST: guidelines for response criteria for use in trials testing immunotherapeutics. Lancet Oncol. 2017;18(3):e143-e152.

42. Choi JH, Ahn MJ, Rhim HC, et al. Comparison of WHO and RECIST criteria for response in metastatic colorectal carcinoma. Cancer Res Treat. 2005;37(5):290-293.

43. Eisenhauer EA, Therasse P, Bogaerts J, et al. New response evaluation criteria in solid tumours: revised RECIST guideline (version 1.1). Eur J Cancer. 2009;45(2):228-247.

44. Harrington KJ, Andtbacka RHI, Collichio F, et al. Benefit and risk analysis from the phase III OPTiM trial of talimogene laherparepvec (T-VEC) vs granulocyte-stimulating factor (GM-CSF) in patients with stage IIIB-IV melanoma. Poster presented at: 11th European Association of Dermato Oncology (EADO) Congress and 8th World Meeting of Interdisciplinary Melanoma/Skin Cancer Centers, Marseille, France; October 28-31, 2015.

45. World Health Organization. Laboratory Biosafety Manual. 3rd ed. 2004. Available from: http://www.who.int/csr/resources/publications/ biosafety/en/Biosafety7.pdf. Accessed October 3, 2016.

46. Rehman H, Silk AW, Kane MP, Kaufman HL. Into the clinic: talimogene laherparepvec (T-VEC), a first-in-class intratumoral oncolytic viral therapy. J Immunother Cancer. 2016;4:53.

patient perspectives such as quality of life, adherence and satisfaction The manuscript management system is completely online and includes a very quick and fair peer-review system, which is all easy to use. Visit http://www.dovepress.com/testimonials.php to read real quotes from published authors. 